\title{
Transition Experiments on Blunt Bodies with Distributed Roughness in Hypersonic Free Flight in Carbon Dioxide
}

\author{
Michael C. Wilder* and Daniel C. Reda ${ }^{\dagger}$ \\ NASA-Ames Research Center, Moffett Field, CA 94035-1000 \\ and \\ Dinesh K. Prabhu* \\ ERC, Inc., Moffett Field, CA 94035-1000
}

\begin{abstract}
Blunt-body geometries were flown through carbon dioxide in the NASA Ames Hypervelocity Free Flight Aerodynamic Facility to investigate the influence of distributed surface roughness on transition to turbulence in $\mathrm{CO}_{2}$-dominated atmospheres, such as those of Mars and Venus. Tests were also performed in air for direct comparison with archival results. Models of hemispherical and spherically-blunted large-angle conical geometries were flown at speeds between $2.8 \mathrm{~km} / \mathrm{s}$ and $5.1 \mathrm{~km} / \mathrm{s}$ and freestream pressures between 50 Torr and 228 Torr. Transition fronts were determined from global surface heat flux distributions measured using thermal imaging techniques. Distributed surface roughness was produced by grit-blasting the model surfaces. Real-gas Navier-Stokes solutions were used to calculate non-dimensional correlating parameters at the measured transition onset locations. Transition-onset locations correlated well with a constant roughness Reynolds number based on the mean roughness element height. The critical roughness Reynolds number for transition onset determined for flight in $\mathrm{CO}_{2}$ was $223 \pm 25 \%$. This mean value is lower than the critical value of $250 \pm 20 \%$ previously-established from tests conducted in air, but within the bounds of the expected measurement uncertainty.
\end{abstract}

Nomenclature

$\mathrm{k}=$ measured surface roughness element height

$\overline{\mathrm{k}} \quad=$ average roughness element height

$\mathrm{P}_{\infty} \quad=$ free stream static pressure

$\mathrm{R}_{\mathrm{n}} \quad=$ nose radius

$\mathrm{Re}_{\infty} \quad=$ free stream Reynolds number based on nose radius, $\rho_{\infty} V R_{n} / \mu_{\infty}$

$\operatorname{Re}_{\mathrm{kk}} \quad=$ roughness Reynolds number, $\rho_{\mathrm{k}} \mathrm{u}_{\mathrm{k}} \overline{\mathrm{k}} / \mu_{\mathrm{w}}$

$\mathrm{q}=$ convective heat transfer rate

$\mathrm{S} \quad=$ run length from stagnation point

$\mathrm{T}=$ temperature

$\mathrm{u} \quad=$ velocity

$\mathrm{V}=$ model velocity at arbitrary time

$\mathrm{V}_{0} \quad=$ model velocity at launch

$\overline{\mathrm{V}} \quad=$ average model flight velocity

$\mathrm{X} \quad=$ disturbance parameter, $\left[\rho_{\mathrm{k}} \mathrm{u}_{\mathrm{k}} / \rho_{\mathrm{e}} \mathrm{u}_{\mathrm{e}}\right] \overline{\mathrm{k}} / \theta$

$\mathrm{Y}_{\mathrm{tr}} \quad=$ transition Reynolds number, $\left[\rho_{\mathrm{e}} \mathrm{u}_{\mathrm{e}} \theta / \mu_{\mathrm{w}}\right]_{\mathrm{tr}}$

$\mathrm{x}, \mathrm{y}, \mathrm{z}=$ local surface coordinates

$\delta \quad=$ laminar boundary layer thickness

$\theta \quad=$ laminar boundary layer momentum thickness

$\phi \quad=$ angular position on sphere segment measured from stagnation point

\footnotetext{
* Senior Research Scientist, Aerothermodynamics Branch, MS 230-2; Associate Fellow, AIAA.

$\dagger$ Senior Research Scientist, Aerothermodynamics Branch, (retired); Fellow, AIAA.

* Senior Staff Scientist, ERC, Inc.; Associate Fellow, AIAA.
} 


$$
\begin{array}{ll}
\rho & =\text { fluid density } \\
\sigma & =\text { standard deviation } \\
\mu & =\text { fluid viscosity }
\end{array}
$$

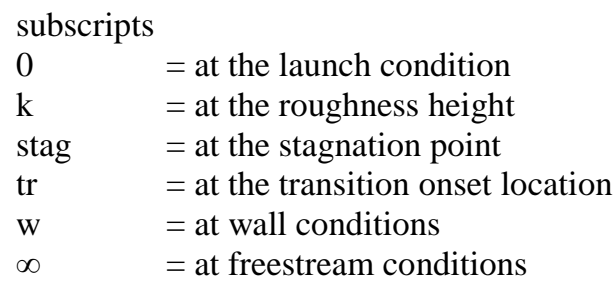

\section{Introduction}

MDELING of roughness-dominated transition is an important design issue for many ablating thermal protection systems (TPS). Ablating TPS materials used for planetary-entry and Earth-return missions first experience recession under high-altitude, low-Reynolds-number conditions. Such laminar-flow ablation causes the formation of a distributed surface microroughness pattern characteristic of the TPS material. Once formed, these distributed surface roughness elements create disturbances within the laminar boundary layer flowing over the surface. As altitude decreases, Reynolds number increases, and flow field conditions capable of amplifying these roughness-induced perturbations are eventually achieved, resulting in the onset of transition. Depending on the particular circumstances, roughness-induced transition may occur earlier in the entry trajectory than natural, smoothwall transition would be expected. Boundary-layer transition to turbulence results in more severe heat transfer rates and skin friction, which can impact the design requirements of the heatshield.

In a review of roughness-dominated transition correlations for reentry applications Reda ${ }^{1}$ showed that the critical-roughness-Reynolds-number concept hypothesized by Schiller ${ }^{2}$ successfully described data on blunt bodies, attachment lines, and windward surfaces of lifting entry vehicles; however, the critical value differed for different configurations. That is, no universal value existed for the critical roughness Reynolds number for transition to turbulence for all possible geometry and flow field combinations. The critical roughness Reynolds number for transition, $\operatorname{Re}_{\mathrm{kk}, \mathrm{tr}}=\left(\rho_{\mathrm{k}} \mathrm{u}_{\mathrm{k}} \mathrm{k} / \mu_{\mathrm{w}}\right)_{\mathrm{tr}}$, is based on laminar boundary-layer parameters evaluated at the location of transition onset and at the characteristic roughness height. For small roughness, the elements can be assumed to be at the wall temperature, hence, the fluid viscosity is evaluated at the wall temperature.

The transition correlation of Reda, et al. ${ }^{3}$ for blunt bodies with distributed roughness in hypersonic flight through air is shown in Fig. 1. The critical value for roughness-dominated transition was determined to be $\operatorname{Re}_{\mathrm{kk}}$, tr $=250 \pm 20 \%$. The large-roughness asymptote represents conditions where the transition front has moved as close as physically possible to the stagnation point. The roughness character in experiments of Ref. 3 was sand-grainlike, produced either by pre-ablating graphite materials under laminar flow conditions in an arcjet prior to flying in the ballistic range, or by mechanically roughening by blasting the surface with abrasive grit.

Additional ballistic-range experiments ${ }^{4}$ found that the critical roughness-Reynolds-number correlating approach also applied to roughnessdominated transition on the frusta of blunted cones in which the boundary-layer edge conditions were supersonic. These experiments were conducted on a $30^{\circ}$ half-angle cone at $0^{\circ}$ angle of attack, having a grit-blast surface roughness. The critical value of $\mathrm{Re}_{\mathrm{kk}}$ was, within the measurement uncertainty, equal to that found for blunt bodies.

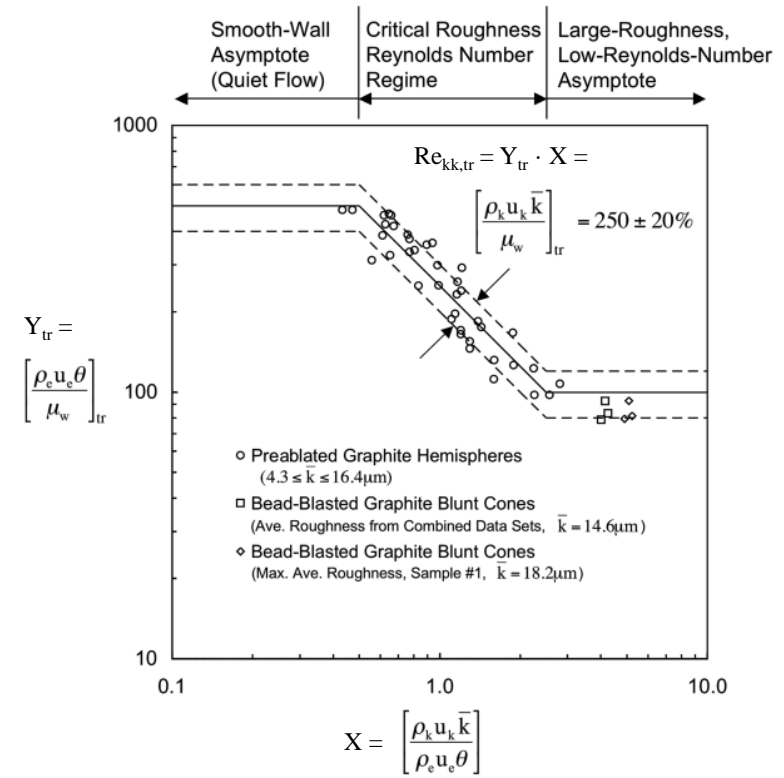

Figure 1. Transition correlation for blunt bodies with distributed roughness in hypersonic free flight in air from Ref. 3. 
More recently, Hollis ${ }^{5}$ reported a series of hypersonic wind-tunnel experiments on hemispheres and $70^{\circ}$ spherecones with both sand-grain roughness and patterned roughness (arrays of hemispherical elements arranged in a regular pattern). The $70^{\circ}$ sphere-cone geometry has been used for every NASA Mars entry vehicle, and was tested at a $16^{\circ}$ angle of attack, representative of the recent Mars Science Laboratory (MSL) entry. Transition location measurements for sand-grain roughness made on the hemispheres, and along the centerline of the sphere-cones, correlated well with the roughness Reynolds number, $\mathrm{Re}_{\mathrm{kk}}$, and the critical value in the roughness-dominated regime was in reasonable agreement with Fig. 1. The large-roughness asymptote, however, was not observed. Instead, the constant critical roughness Reynolds number trend continued for larger values of the disturbance parameter, $\mathrm{X}$. Also, the transition location for patterned roughness (tested only on the sphere-cone geometry) did not appear to correlate with a constant critical roughness Reynolds number. It should be noted that the characteristic roughness height used for the patterned roughness distributions was that of an equivalent sand-grain roughness as determined using the correlation of Dirling. ${ }^{6}$ This correlation was developed for interpreting the effects of patterned roughness on turbulent boundary layers, and its applicability to laminar boundary layer profiles used in the critical roughness Reynolds number correlating approach has not been demonstrated.

Prior to the MSL entry, roughness-dominated transition was not an issue for Mars entry missions. Data returned from the instrumented heatshield of the MSL entry vehicle, the largest Mars entry vehicle to date, indicated the presence of roughness-induced transition on the leeward face of the forebody heatshield. As reported by White, et $a l .{ }^{7}$ the rapid progression of the turbulent transition front from the leeward shoulder to the nose cap was not well predicted by existing smooth wall transition criteria, but may be explained through roughness induced transition. Although the results of Hollis ${ }^{5}$ and Reda ${ }^{4}$ support the applicability of the critical roughness Reynolds number correlating approach on the frustum of a sphere-cone with a sand-grain roughness, the value of the critical roughness Reynolds number for the MSL entry was an outstanding question at the time of the analysis of Ref. 7.

In prior experiments ${ }^{8}$ to extend the critical roughness Reynolds number correlating approach to the interpretation of transition due to isolated roughness elements on blunt bodies, a different critical roughness Reynolds number was found for tests conducted in $\mathrm{CO}_{2}$ than for those conducted in air, with the critical value for an isolated trip found to be approximately 1.3 times lower in $\mathrm{CO}_{2}$ than in air. This same ratio was applied to the blunt-body correlation for distributed surface roughness of Fig. 1 in the analysis of the MSL data, ${ }^{7}$ resulting in a presumed critical $\mathrm{Re}_{\mathrm{kk}}$ for distributed roughness in $\mathrm{CO}_{2}$ of approximately 190 . Whether this ratio was applicable to the situation of distributed surface roughness was unknown at the time. Mean roughness heights in the "critical roughness Reynolds number regime" of Fig. 1 tend to be on the scale of the momentum thickness $(\mathrm{k} / \delta<0.2)$, while transition onset due to an isolated roughness element (Ref. 8) required roughness heights larger than the momentum thickness.

In order to help improve the roughness-induced transition criterion for future Mars or Venus entry vehicles, hypersonic ballistic-range experiments were conducted in $\mathrm{CO}_{2}$ on blunt bodies with distributed surface roughness, and the results are reported herein. Hemispheres and two sphere-cone geometries were tested, however, transition always occurred on the sphere-segment nose cap of the sphere-cones geometries. Real-gas Navier-Stokes calculations were performed of smooth-wall laminar and turbulent flow at the measured test conditions, from which non-dimensional correlating parameters were calculated at the measured transition onset locations. Tests were also conducted in air for comparison with the established correlation shown in Fig. 1. The roughness distributions were sand-grain-like, produced by grit-blasting the model surfaces. Each roughness distribution was characterized using topographical analysis of 3D surface scans.

\section{Experimental Approach}

\section{A. Test Facility}

The experiments were performed in the Hypervelocity Free Flight Aerodynamic Facility (HFFAF) ballistic range at NASA Ames Research Center. The facility employs a suite of interchangeable guns to launch model entry vehicles through an enclosed test section filled with a quiescent test gas at ambient room temperature. The testsection pressure and gas composition are controllable to allow simulation of flight through different planetary atmospheres, ${ }^{9}, 10$ and to allow independent variation of Mach and Reynolds numbers. The tests reported herein employed a two-stage light-gas gun with an inner diameter of $38.1 \mathrm{~mm}$ (1.5 in), capable of launch velocities as high as $9 \mathrm{~km} / \mathrm{s} .{ }^{11}$ The test section, shown in Fig. 2, is approximately $1 \mathrm{~m}$ across and $23 \mathrm{~m}$ long. There are 16 spark shadowgraph stations along the test section, evenly spaced every $1.524 \mathrm{~m}$ ( 5 feet). Each station provides orthogonal side- and top-view shadowgraphs, from which the instantaneous position and orientation of the projectile can be measured. Elapsed-time data provided by 16 high-speed digital counters, synchronized with the shadowgraphs, 


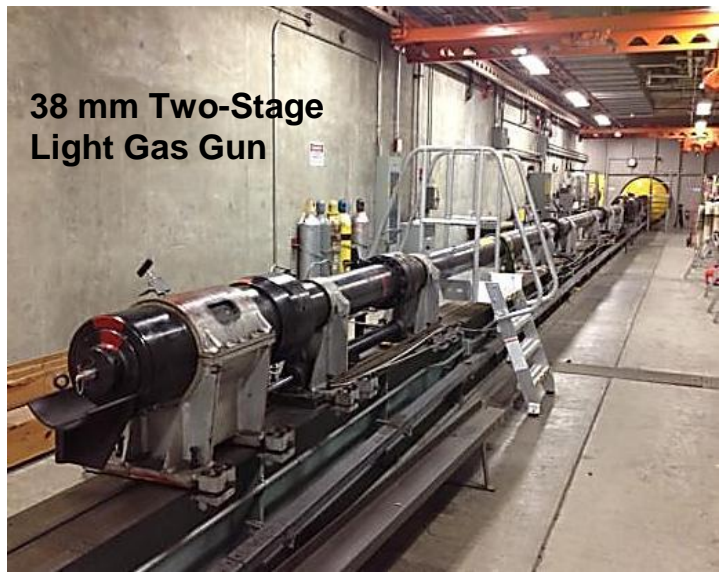

(a)

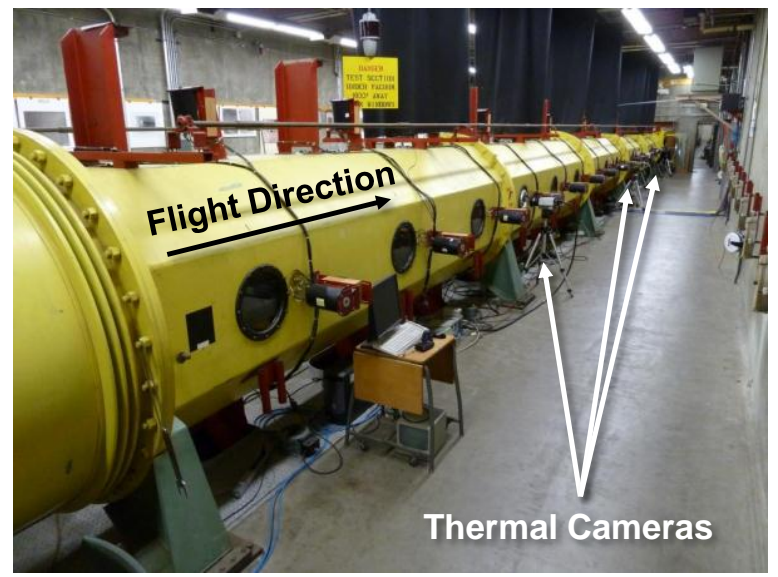

(b)

Figure 2. The HFFAF ballistic range at NASA Ames Research Center.

allow the 6-degree-of-freedom trajectories to be determined. Further details about the facility can be found in Refs. 11 and 12 .

\section{B. Computational Method}

Laminar and turbulent solutions were generated using the Data Parallel Line Relaxation $(D P L R)$ code $^{13}$ for an axisymmetric geometry. A 5-species chemically reacting model was employed for the test gas: $\mathrm{CO}_{2}, \mathrm{CO}, \mathrm{O}_{2}, \mathrm{C}$, and $\mathrm{O}$ for the carbon dioxide cases, and $\mathrm{N}_{2}, \mathrm{O}_{2}, \mathrm{NO}, \mathrm{N}$, and $\mathrm{O}$ for the air cases. In all computations thermal equilibrium (i.e., a single temperature) was assumed and thermodynamic properties (enthalpy and specific heat) of constituent species were determined using GRC curve fits. ${ }^{14}$ All cases were computed with a prescribed wall temperature. For the air cases the wall was assumed to be fully catalytic to recombination of atomic species ( $\mathrm{N}$ and $\mathrm{O}$ ), and for the carbon dioxide cases only recombination of atomic oxygen was considered. Turbulent-flow computations employed the simple algebraic turbulence model of Baldwin and Lomax. ${ }^{15}$ In the present work, pre-test computations were performed for a range of wall temperatures spanning the expected range, and post-test computations were performed for wall temperatures at launch and at those measured at the transition onset locations.

Figure 3 shows pre-test computed roughness Reynolds number distributions on a hemisphere of $R_{n}=14.29 \mathrm{~mm}$ at $5.13 \mathrm{~km} / \mathrm{s}$ with a wall temperature of $950 \mathrm{~K}$ for several mean roughness heights and freestream pressures. These computations were used to guide selection of roughness heights and freestream pressures for the experiments. A

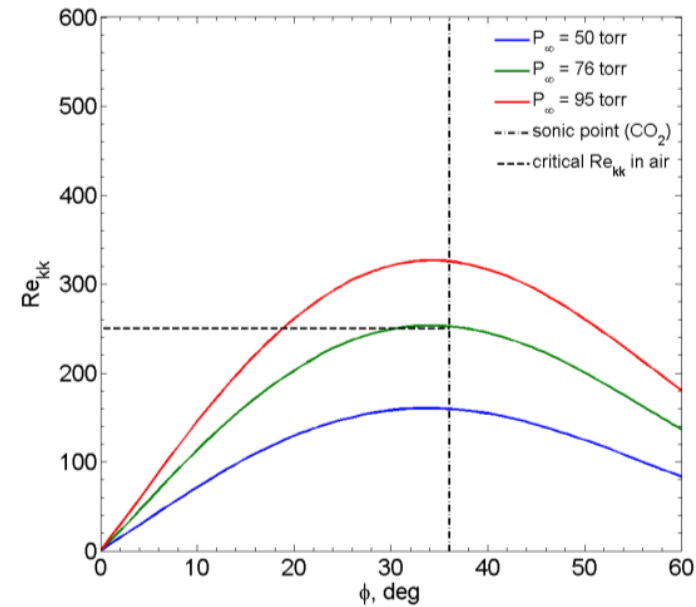

(a)

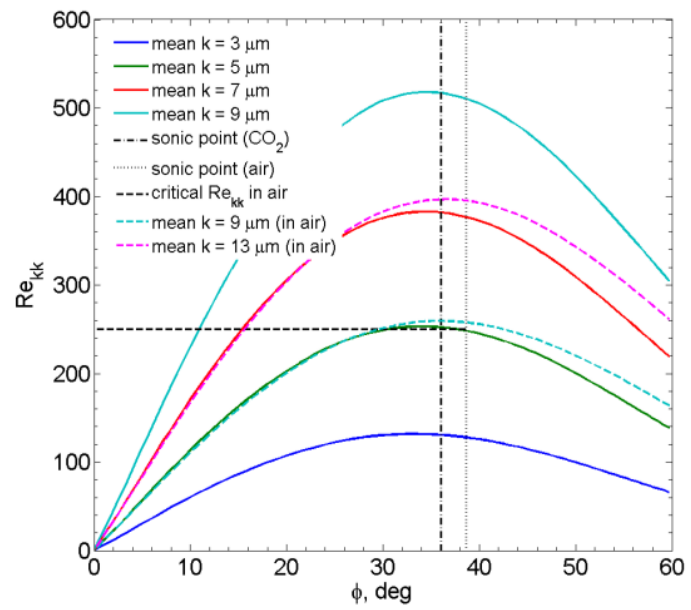

(b)

Figure 3. Computed roughness Reynolds number distributions on a hemisphere, $R_{n}=14.29 \mathrm{~mm}$, $\mathrm{V}_{0}=5.13 \mathrm{~km} / \mathrm{s}, \mathrm{T}_{\mathrm{w}}=950 \mathrm{~K}$ : (a) in $\mathrm{CO}_{2}$ at various freestream pressures for roughness height of $5 \mu \mathrm{m}$; (b) in $\mathrm{CO}_{2}$ and air at 76 Torr for various roughness heights. 
velocity around $5 \mathrm{~km} / \mathrm{s}$ was selected as representative of a Mars entry condition (a launch velocity of $5.13 \mathrm{~km} / \mathrm{s}$ was expected to give a mid-range velocity of $5 \mathrm{~km} / \mathrm{s}$ ). Also shown in Fig. 3 are the critical roughness Reynolds number in air $\left(\mathrm{Re}_{\mathrm{kk}}=250\right)$, and the sonic points for $\mathrm{CO}_{2}$ and air, beyond which the boundary-layer edge velocity is supersonic. Figure 3a shows that, for a given roughness height, the local roughness Reynolds number increases with freestream Reynolds number (or freestream pressure), and that the critical $\mathrm{Re}_{\mathrm{kk}}$ is first reached at the sonic point. Figure $3 \mathrm{~b}$ shows that, for a given test condition, local $\mathrm{Re}_{\mathrm{kk}}$ increases with increasing roughness height, moving the transition onset closer to the stagnation point. Figure $3 \mathrm{~b}$ also shows that, for the same velocity and freestream pressure, it is expected that a larger roughness height is required in air to achieve the same value of $\mathrm{Re}_{\mathrm{kk}}$ as in $\mathrm{CO}_{2}$. This ratio of roughness height is equal to the ratio of boundary-layer thickness in the two gases, $\delta_{\text {air }} / \delta_{\mathrm{CO}_{2}} \sim 1.8$.

Figure 4 shows similar $\operatorname{Re}_{\mathrm{kk}}$ distributions computed for the $45^{\circ}$ sphere-cone geometry tested in $\mathrm{CO}_{2}$. At $0^{\circ}$ angle of attack the local value of $\mathrm{Re}_{\mathrm{kk}}$ decreases rapidly moving onto the conic frustum. For a distributed roughness of uniform height, the critical value of $\mathrm{Re}_{\mathrm{kk}}$ for transition is expected to occur first on the spheresegment nose cap. These sphere-cone models were the subjects of experiments to study the roughness augmentation of turbulent heat transfer on the conic frusta of blunt cones, as reported in Ref. 16. Distributed roughness was applied to the nose cap to ensure a fully-developed turbulent boundary layer on the cone. As a consequence, those tests also yielded roughness-induced transition data reported herein.

\section{Ballistic-Range Models and Surface Roughness Characterization}

Three model geometries were tested: hemisphere, $45^{\circ}$ sphere-cone, and $30^{\circ}$ sphere-cone (tested in air only). As discussed above, roughness-induced transition occurred on the sphere-segment nose cap of the sphere-cone geometries in all cases. Figure 5 shows a shadowgraph of each model type in flight. The hemisphere models were made of stainless steel alloy 304 and had a nose radius $R_{n}=14.29 \mathrm{~mm}$. The $45^{\circ}$ sphere-cone models were made of titanium alloy Ti-6Al-4V and had a nose radius $R_{n}=7.62 \mathrm{~mm}$ and a base radius of $16.51 \mathrm{~mm}$. The $30^{\circ}$ sphere-cone models were made of stainless steel alloy 304 , had a nose radius $R_{n}=7.62 \mathrm{~mm}$ and a base radius of $15.13 \mathrm{~mm}$. The $30^{\circ}$ sphere-cone models were also part of the experiments reported in Ref. 16, and were tested in air only.

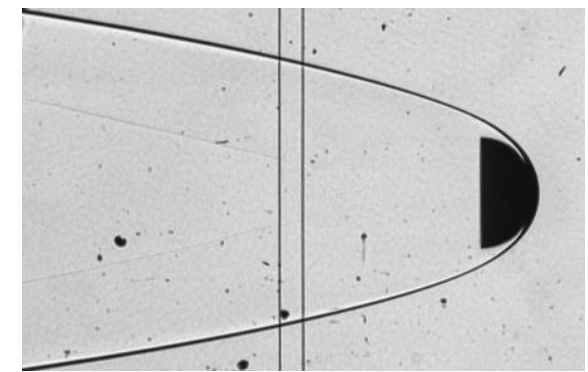

(a)

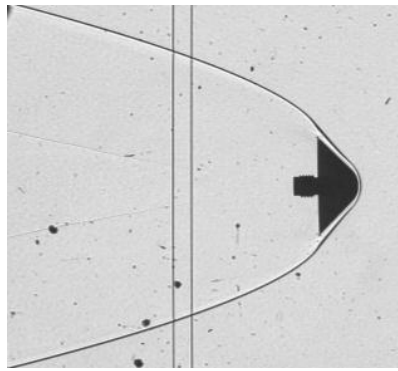

(b)

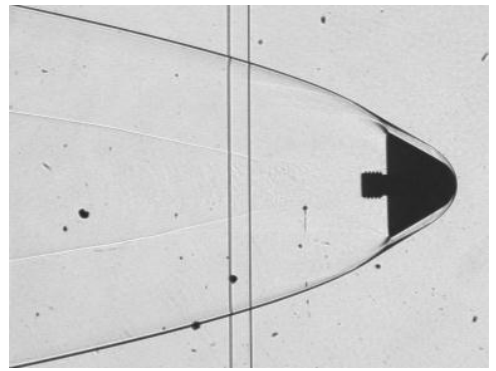

(c)

Figure 5. Shadowgraphs illustrating model geometries: (a) hemisphere, $R_{\mathrm{n}}=14.29 \mathrm{~mm}$; (b) $45^{\circ} \mathrm{sphere}$ cone, $R_{\mathbf{n}}=7.62 \mathrm{~mm}$; (c) $30^{\circ}$ sphere-cone, $R_{\mathbf{n}}=7.62 \mathrm{~mm}$.

The models were roughened using grit-blasting techniques described in Refs. 4 and 16. Resultant surface roughness patterns were measured by confocal microscopy, producing 3D surface maps of regions on each model. The quoted resolution of the instrument was $6 \mathrm{~nm}$ in the direction normal to the surface $(\mathrm{z})$, and $1.6 \mu \mathrm{m}$ in the 
transverse directions (x, y). A representative measurement is shown in Fig. 6. Topographical analysis $^{4}$ was performed on the measured surface elevation maps to identify individual roughness elements. The height, $\mathrm{k}$, of an element was defined as the vertical distance from the peak of the element to the lowest point in the valley (or trough) between it and neighboring elements. Roughness element height distributions obtained from this analysis are shown in Fig. 7 as probability-of-exceedance distributions (a), and as probability of occurrence distributions (b). For evaluating the roughness Reynolds number, each roughness distribution was characterized by the arithmetic average of the measured roughness element heights, $\overline{\mathrm{k}}$.

This technique produced a roughness distribution similar in appearance to a sand-grain roughness, and with probability-of-exceedance distributions like those of ablated graphite materials discussed in Ref. 3 and used to develop the critical roughness Reynolds number correlation shown in Fig. 1. Therefore, it is

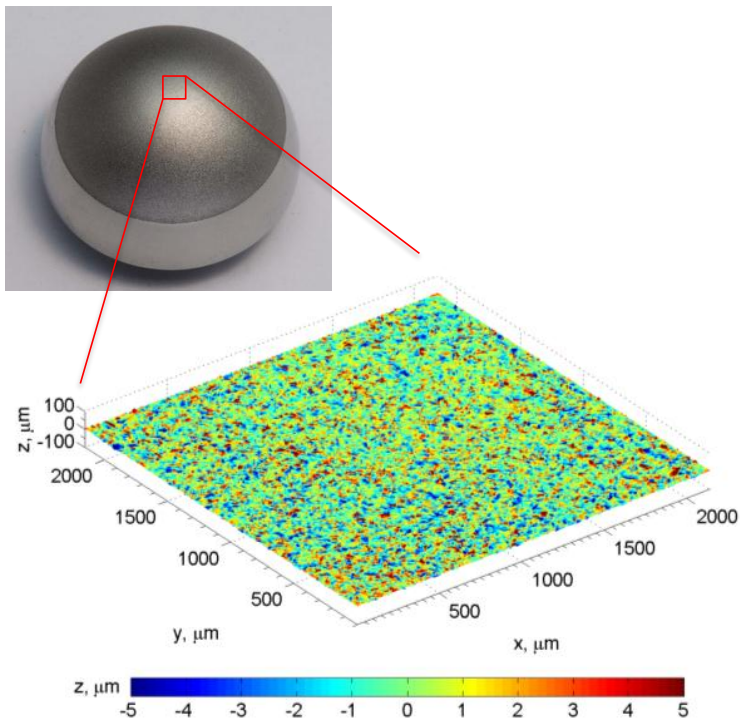

Figure 6. Example surface elevations measured on grit-blasted hemisphere.

expected that the correlation shown in Fig. 1 will be valid on blunt bodies tested in air having grit-blasted roughness distributions. A number of tests were conducted in air to verify this assumption, and results are presented in following sections.

A typical roughened model of each type is shown in Fig. 8. Roughness on the hemispheres extended only to $60^{\circ}$ from the stagnation point. The test conditions and characteristic roughness heights for tests made in $\mathrm{CO}_{2}$ are given in Table 1, and for tests made in air in Table 2. All tests were conducted at a mean angle of attack of zero degrees. In

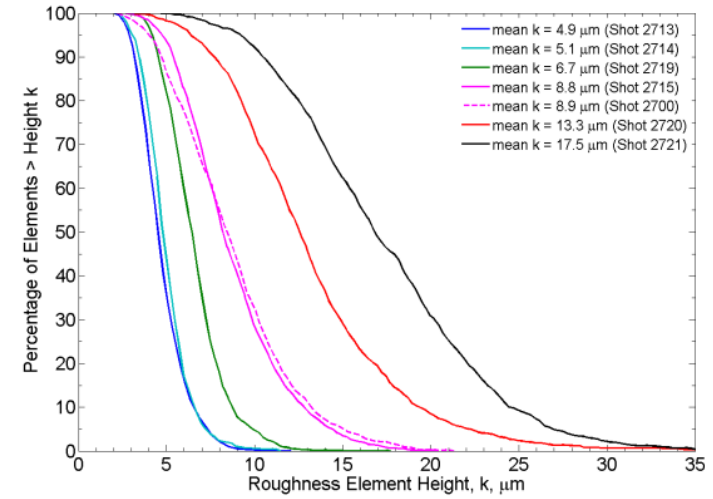

(a)

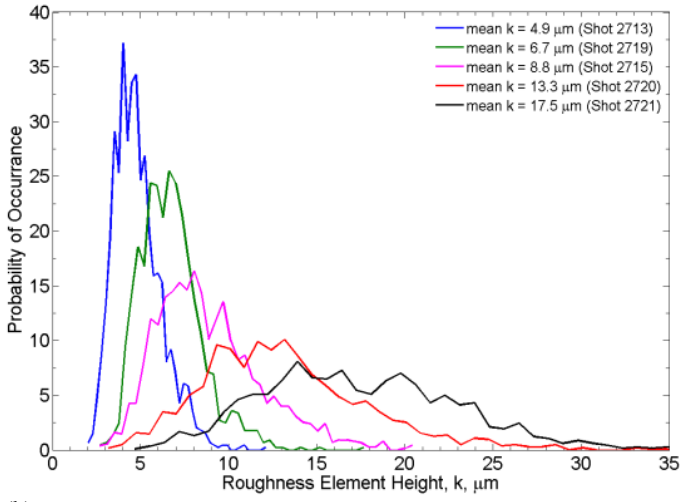

(b)

Figure 7. Measured roughness element height distributions for set of grit-blasted steel hemispheres tested in $\mathrm{CO}_{2}$ : (a) displayed as probability of exceedance; (b) displayed a probability of occurrence distribution.

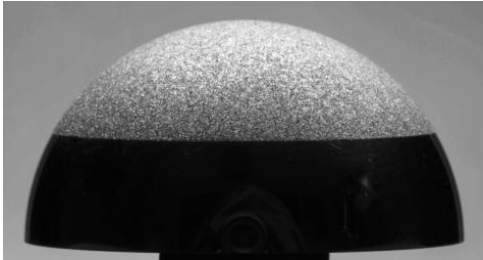

(a)

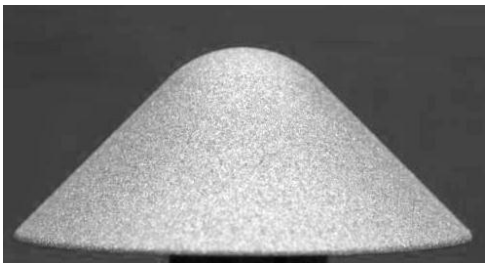

(b)

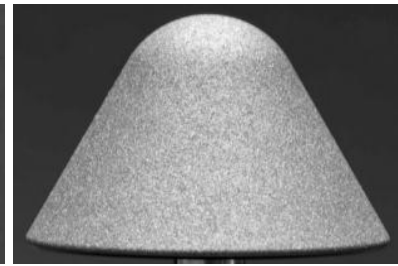

(c)

Figure 8. Example rough models: (a) hemisphere, $R_{n}=14.29 \mathrm{~mm}$; (b) $45^{\circ}$ sphere-cone, $R_{\mathbf{n}}=7.62 \mathrm{~mm}$; (c) $30^{\circ}$ sphere-cone, $R_{n}=7.62 \mathrm{~mm}$. 
flight, the models oscillated slightly, executing between one and two oscillation cycles over the course of the flight. Typical maximum angles of attack were less than 2 degrees. Measured transition fronts were symmetrical, within the deviation expected for roughness distribution of these types. ${ }^{17}$

Table 1. Test conditions and characteristic roughness heights for tests in $\mathrm{CO}_{2}$.

\begin{tabular}{|c|c|c|c|c|c|c|c|c|}
\hline Shot No. & $\mathrm{V}_{0}, \mathbf{k m} / \mathbf{s}$ & $\overline{\mathbf{V}}, \mathbf{k m} / \mathbf{s}$ & $\mathbf{P}_{\infty}$, Torr & $\mathbf{M}_{\infty}$ & $\begin{array}{c}\mathbf{R e}_{\infty} \\
\left(\times \mathbf{1 0}^{-6}\right)\end{array}$ & $\overline{\mathbf{k}}, \boldsymbol{\mu m}$ & $\sigma(\overline{\mathbf{k}}), \mu \mathbf{m}$ & Model Type \\
\hline 2700 & 5.13 & 5.05 & 50.0 & 19.14 & 0.59 & 8.9 & 3.4 & \multirow{7}{*}{ Hemisphere } \\
\hline 2713 & 5.03 & 4.91 & 76.0 & 18.80 & 0.88 & 4.9 & 1.4 & \\
\hline 2714 & 5.05 & 4.92 & 76.0 & 18.84 & 0.88 & 5.1 & 1.3 & \\
\hline 2715 & 5.02 & 4.93 & 76.0 & 18.72 & 0.87 & 8.8 & 2.9 & \\
\hline 2719 & 5.17 & 5.05 & 76.0 & 19.27 & 0.90 & 6.7 & 1.7 & \\
\hline 2720 & 5.04 & 4.93 & 75.9 & 18.83 & 0.88 & 13.3 & 4.9 & \\
\hline 2721 & 5.07 & 4.96 & 76.0 & 18.93 & 0.89 & 17.5 & 5.7 & \\
\hline 2708 & 2.88 & 2.70 & 76.5 & 10.72 & 0.27 & 12.4 & 5.9 & \multirow{4}{*}{$45^{\circ}$ sphere-con } \\
\hline 2716 & 2.94 & 2.74 & 76.0 & 10.96 & 0.27 & 8.3 & 2.6 & \\
\hline 2717 & 2.87 & 2.71 & 76.2 & 10.70 & 0.27 & 6.4 & 2.1 & \\
\hline 2718 & 2.89 & 2.73 & 76.1 & 10.76 & 0.27 & 13.0 & 5.2 & \\
\hline
\end{tabular}

Table 2. Test conditions and characteristic roughness heights for tests in air.

\begin{tabular}{|c|c|c|c|c|c|c|c|c|}
\hline Shot No. & $\mathrm{V}_{0}, \mathbf{k m} / \mathbf{s}$ & $\overline{\mathbf{V}}, \mathbf{k m} / \mathbf{s}$ & $\mathbf{P}_{\infty}$, Torr & $\mathbf{M}_{\infty}$ & $\begin{array}{c}\operatorname{Re}_{\infty} \\
\left(\times 1^{-6}\right)\end{array}$ & $\overline{\mathbf{k}}, \boldsymbol{\mu m}$ & $\sigma(\overline{\mathbf{k}}), \mu \mathbf{m}$ & Model Type \\
\hline 2711 & 3.95 & 3.87 & 95.0 & 11.46 & 0.46 & 16.1 & 6.1 & Hemisphere \\
\hline 2683 & 3.60 & 3.49 & 228.0 & 10.52 & 0.54 & 5.1 & 2.2 & \multirow{6}{*}{$30^{\circ}$ sphere-cone } \\
\hline 2684 & 3.59 & 3.48 & 228.0 & 10.52 & 0.55 & 6.0 & 2.9 & \\
\hline 2685 & 3.59 & 3.48 & 228.0 & 10.52 & 0.55 & 6.0 & 2.9 & \\
\hline 2686 & 3.53 & 3.42 & 228.0 & 10.30 & 0.53 & 14.7 & 5.9 & \\
\hline 2687 & 3.47 & 3.35 & 228.0 & 10.14 & 0.53 & 9.7 & 2.5 & \\
\hline 2689 & 3.55 & 3.46 & 228.0 & 10.35 & 0.53 & 16.4 & 5.3 & \\
\hline 2697 & 3.18 & 2.96 & 114.0 & 9.28 & 0.24 & 15.3 & 5.3 & \multirow{7}{*}{$45^{\circ}$ sphere-cone } \\
\hline 2699 & 3.16 & 2.95 & 114.0 & 9.18 & 0.23 & 23.7 & 8.5 & \\
\hline 2701 & 3.13 & 2.92 & 114.0 & 9.06 & 0.23 & 22.7 & 8.7 & \\
\hline 2703 & 3.14 & 2.94 & 114.0 & 9.07 & 0.23 & 17.3 & 5.3 & \\
\hline 2704 & 3.12 & 2.92 & 113.9 & 9.07 & 0.23 & 15.9 & 5.4 & \\
\hline 2706 & 2.99 & 2.79 & 114.0 & 8.69 & 0.22 & 16.8 & 5.9 & \\
\hline 2707 & 2.95 & 2.78 & 114.0 & 8.56 & 0.22 & 16.3 & 5.7 & \\
\hline
\end{tabular}

\section{Thermal Imaging and Data Analysis}

Instantaneous global surface temperature distributions on the models were recorded with three thermal imaging cameras, sensitive to the 3-5 $\mu \mathrm{m}$ infrared wavelength band. Each camera was calibrated against a blackbody source on an optical path equivalent to that of the ballistic-range tests, as discussed in Ref. 18. From these calibrations, and knowledge of the emissivity of the model material, image intensity was converted to surface temperature. The standard deviation of the calibration data was, on average, around $1.1 \%$. 
The cameras were placed at three locations along the flight path (beginning, middle, and end of the test section), and arranged to image the models from an angle between 20 and $25 \mathrm{deg}$ off the nominal flight line, or as nearly head on as possible. All images were recorded with a $1 \mu$ s exposure time, and exposure level was controlled with optical filters. Motion blur at the highest test speeds was approximately 2 pixels, or between 4 and $6 \%$ of the model length. The standard deviation in the transition-front location, when averaged circumferentially around a model, was on average less than $5 \%$ of the model length.

Photogrammetric techniques (discussed in Ref. 8) were employed to map the images to the 3D surface grid defining the model geometry, from which spatial measurements could be made. Working with the grid-mapped images, the transition onset location was found on 360 profiles (every 1 degree circumferentially around the model), resulting in the instantaneous transition front for that image. The onset of transition was identified as the location along any given axial profile where the heat flux exceeded the laminar heat flux by $10 \%$. Since smooth-wall measurements were not made for all configurations, the computed laminar heat flux was used as the baseline. All heat-flux profiles, measurements and computed, were normalized by the stagnation-point value to remove run-to-run variations.

Heat flux was determined from the measured surface temperatures, assuming one-dimensional conduction at the model surface and using the temperature-dependent thermo-physical properties of the material from which the models were fabricated, as discussed in Ref. 18. Measurement uncertainty is $\pm 10 \%$ based on the standard deviation of stagnation-point heat flux measurements averaged over numerous runs. This includes uncertainty from run-to-run variations in test conditions, such as launch speed.

\section{Results}

Figure 9 shows the images taken at the mid-range point for several of the hemispheres tested in $\mathrm{CO}_{2}$, and illustrates the progression of the transition front towards the stagnation point with increasing roughness height (or increasing freestream Reynolds number). Transition is indicated by an abrupt increase in surface temperature (or brightness, in these images). The transition front becomes ragged for small roughness heights (or low freestream Reynolds number), approaching the small-roughness asymptote of Fig. 1, below which the roughness becomes an ineffective trip. This is reflective of the statistical distribution of the surface roughness element heights. ${ }^{17}$ Surfacemapped heat-flux distributions are shown in Fig. 10 for the tests illustrated in Fig. 9. Shot 2700 (Fig. 10b) was

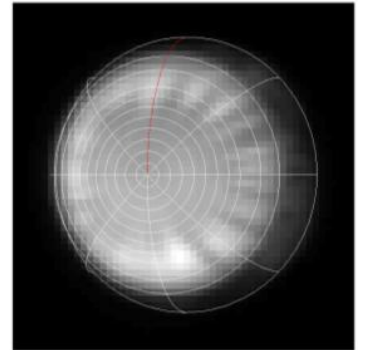

(a) shot 2719

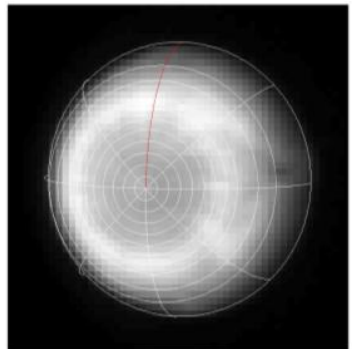

(b) shot 2700

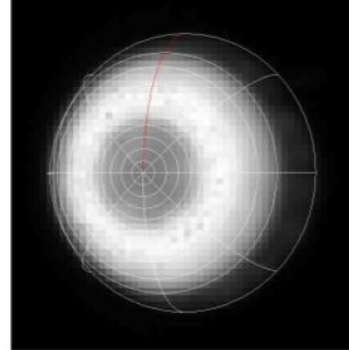

(c) shot 2715

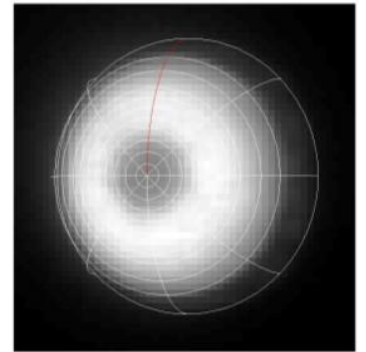

(d) shot 2720

Figure 9. Infrared images taken at the mid-flight station, illustrating the progression of the transition front towards the stagnation point with increasing roughness height (or increasing freestream Reynolds number).

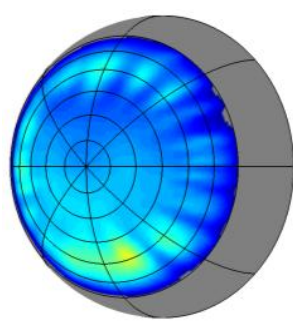

(a) shot 2719

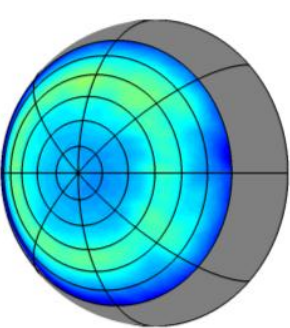

(b) shot 2700

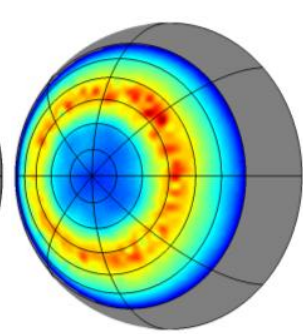

(c) shot 2715

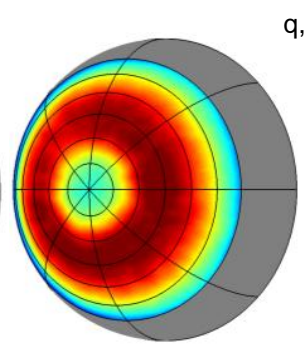

(d) shot 2729 q, W/cm²

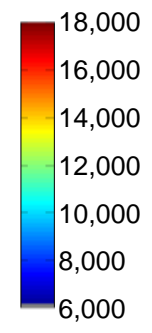

Figure 10. Heat-flux distributions on hemispheres determined for representative tests in $\mathrm{CO}_{2}$. 
conducted at a lower freestream pressure than the other shots in this figure. For comparison, the heat flux values shown here for shot 2700 have been scaled by the square root of the ratio of the stagnation pressures for the two test conditions.

Example transition fronts are shown in Fig. 11. Each image is a composite, with the left half acquired early in the flight, and the right half later in the flight, illustrating the stability of the transition location in time. Figure 12 shows the mean heat-flux profiles for all hemisphere shots in $\mathrm{CO}_{2}$, normalized by the stagnation-point heat flux in order to remove
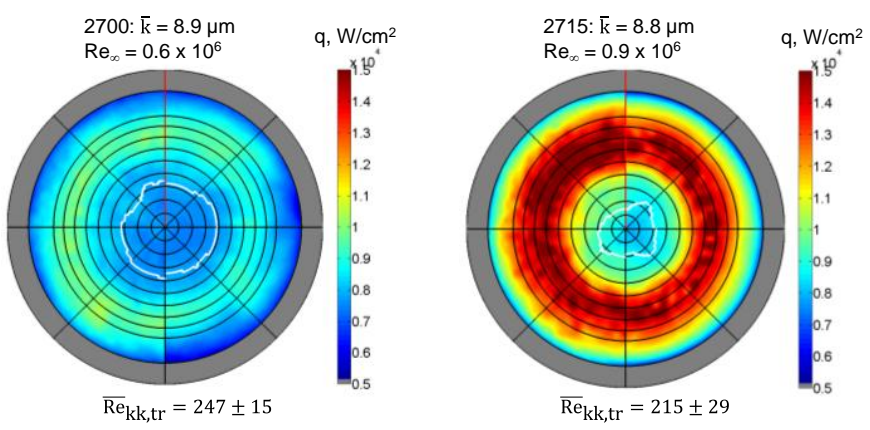

Figure 11. Transition fronts on hemispheres for representative tests in $\mathrm{CO}_{2}$. shot-to-shot variations. Progression of the transition location towards the stagnation point with increasing roughness height can be seen. Also evident is the augmentation of the turbulent heat flux for the larger roughness heights. The mean transition front locations for all shots are given in Tables 3 and 4 for tests conducted in $\mathrm{CO}_{2}$ and in air, respectively. These values are presented in terms of surface run length measured from the stagnation point, normalized by the nose radius, $\mathrm{s}_{\mathrm{tr}} / \mathrm{R}_{\mathrm{n}}$. The standard deviation, $\sigma\left(\mathrm{s}_{\mathrm{tr}} / \mathrm{R}_{\mathrm{n}}\right)$, represents the degree of asymmetry in the transition front. The mean transition front locations are also given in terms of the angle from the stagnation point, $\phi$.

Post-test laminar CFD solutions were computed for the test conditions given in Tables 1 and 2 , and prescribed wall temperatures equal to the temperatures measured at the mean transition onset locations given in Tables 3 and 4 . These solutions were used to determine the transition Reynolds number, $\mathrm{Y}_{\mathrm{tr}}$, the disturbance parameter at transition, $\mathrm{X}$, and the roughness Reynolds number at transition, $\mathrm{Re}_{\mathrm{kk}}$, tr. These quantities are given in Table 3 for tests conducted in $\mathrm{CO}_{2}$, and in Table 4 for tests conducted in air, and are plotted in Fig. 13. The results for both test gases are in reasonable agreement with the correlation of $\operatorname{Reda}^{3}$ (previously shown in Fig. 1). The error bars on the data points represent the standard deviation of $\mathrm{X}$ and $\mathrm{Y}_{\mathrm{tr}}$ around the measured transition front for each shot. Considering only test conditions in the roughness-dominated regime, that is, excluding data points that fall on the largeroughness asymptote $(X>2.5)$, the average roughness Reynolds number at transition onset is $\operatorname{Re}_{\mathrm{kk}}$, tr $=259$ for tests conducted in air, and $\mathrm{Re}_{\mathrm{kk}, \mathrm{tr}}=223$ for tests conducted in $\mathrm{CO}_{2}$. While the mean value in $\mathrm{CO}_{2}$ is less than that in air, the difference is less than the measurement uncertainty. Additional tests with roughness heights approaching the smooth-wall asymptote should improve the statistics. Uncertainty in $\mathrm{Re}_{\mathrm{kk}}$, tr was estimated to be $\pm 25 \%$ from the rootsum-square of uncertainties in the velocity, mean roughness height, fluid viscosity at the wall (which is driven by

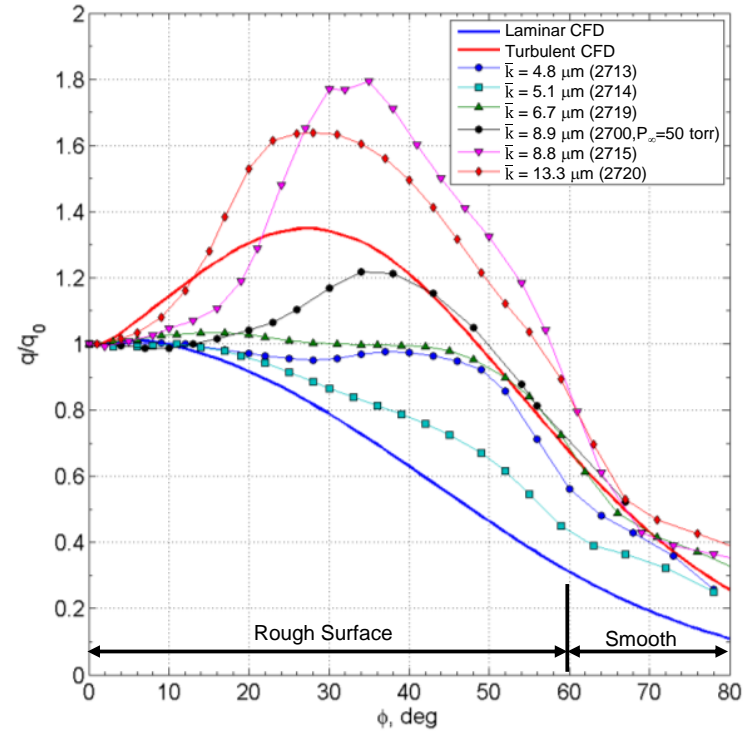

Figure 12. Mean normalized heat flux profiles on rough hemispheres: $5 \mathrm{~km} / \mathrm{s}$, Test Gas $=\mathrm{CO}_{2}$ at 76 Torr (shot 2700 at 50 Torr).

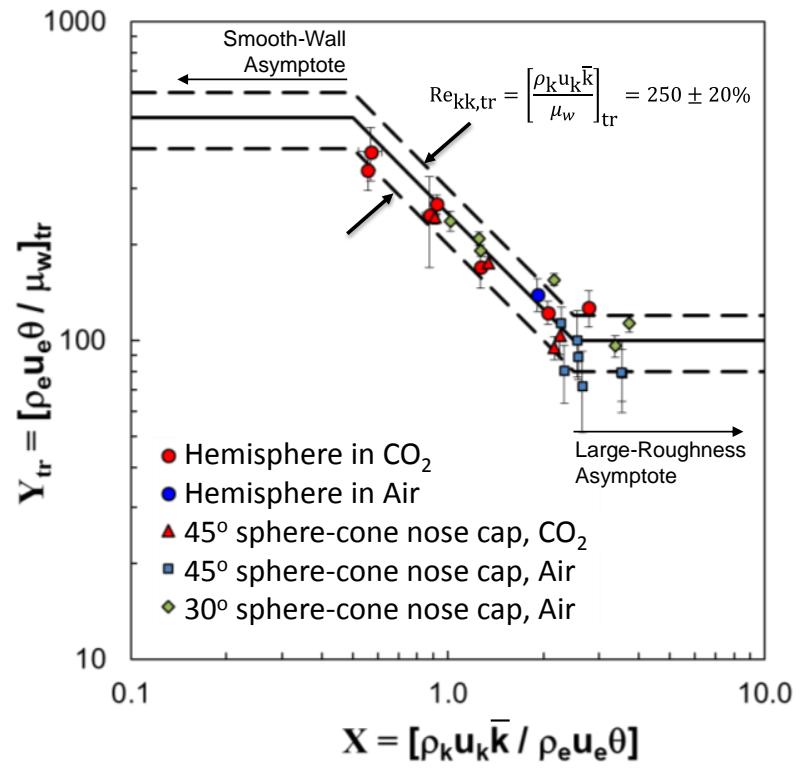

Figure 13. Transition correlation for blunt bodies with distributed roughness in hypersonic free flight in $\mathrm{CO}_{2}$ and in air. 
the uncertainty in measured temperature at the transition location), and the variation in transition location around the transition front (which is dependent on the spatial and temporal resolution of the cameras used).

Table 3. Transition front locations and parameters for tests in $\mathrm{CO}_{2}$.

\begin{tabular}{|c|c|c|c|c|c|c|c|c|c|c|}
\hline $\begin{array}{l}\text { Shot } \\
\text { No. }\end{array}$ & $\mathbf{S t r}_{\mathbf{r}} / \mathbf{R}_{\mathbf{n}}$ & $\sigma\left(\mathbf{S t r}_{\mathbf{r}} / \mathbf{R}_{\mathbf{n}}\right)$ & $\begin{array}{l}\phi \text { tr } \\
\text { deg }\end{array}$ & $\begin{array}{c}\mathbf{T}_{\mathbf{w}, \mathrm{tr}} \\
\mathbf{K}\end{array}$ & $\mathbf{X}$ & $\mathbf{Y}_{\mathrm{tr}}$ & $\mathbf{R e}_{k k, t r}$ & $\sigma\left(\mathbf{R e}_{\mathbf{k} k, \mathrm{tr}}\right)$ & $\overline{\mathrm{k}} / \delta$ & Model Type \\
\hline 2700 & 0.30 & 0.02 & 16.9 & 897 & 0.9 & 267.7 & 246.9 & 14.5 & 0.22 & \multirow{7}{*}{ Hemisphere } \\
\hline 2713 & 0.71 & 0.08 & 21.6 & 1015 & 0.6 & 341.2 & 190.2 & 20.4 & 0.12 & \\
\hline 2714 & 0.45 & 0.11 & 25.7 & 992 & 0.6 & 390.6 & 219.5 & 25.9 & 0.12 & \\
\hline 2715 & 0.18 & 0.03 & 10.6 & 1048 & 1.3 & 169.6 & 214.8 & 28.5 & 0.23 & \\
\hline 2719 & 0.29 & 0.10 & 16.6 & 1078 & 0.9 & 247.3 & 212.6 & 55.8 & 0.17 & \\
\hline 2720 & 0.16 & 0.01 & 9.0 & 1238 & 2.1 & 122.3 & 254.9 & 21.2 & 0.35 & \\
\hline 2721 & 0.16 & 0.02 & 9.3 & 1216 & 2.8 & 126.7 & 355.2 & 44.9 & 0.46 & \\
\hline 2708 & 0.18 & 0.02 & 10.6 & 709 & 2.2 & 94.9 & 205.4 & 16.5 & 0.35 & \multirow{4}{*}{$45^{\circ}$ sphere-cone } \\
\hline 2716 & 0.34 & 0.02 & 19.5 & 671 & 1.3 & 174.9 & 234.6 & 8.6 & 0.22 & \\
\hline 2717 & 0.48 & 0.03 & 27.7 & 645 & 0.9 & 244.2 & 221.8 & 5.2 & 0.15 & \\
\hline 2718 & 0.24 & 0.03 & 13.9 & 872 & 2.3 & 103.8 & 233.8 & 28.5 & 0.36 & \\
\hline
\end{tabular}

Table 4. Transition front locations and parameters for tests in air.

\begin{tabular}{|c|c|c|c|c|c|c|c|c|c|c|}
\hline $\begin{array}{l}\text { Shot } \\
\text { No. }\end{array}$ & $\mathbf{S t r}_{\mathrm{tr}} / \mathbf{R}_{\mathbf{n}}$ & $\sigma\left(\mathbf{s t r}_{\mathbf{r}} / \mathbf{R}_{\mathbf{n}}\right)$ & $\phi_{\mathrm{tr}}, \operatorname{deg}$ & $\underset{\mathbf{K}}{\mathbf{T}_{\mathbf{w}, \mathrm{tr}},}$ & $\mathbf{X}$ & $\mathbf{Y}_{\mathbf{t r}}$ & $\mathbf{R e}_{\mathbf{k}, \mathrm{tr}}$ & $\sigma\left(\mathbf{R e}_{\mathbf{k k}, \mathrm{tr}}\right)$ & $\overline{\mathrm{k}} / \delta$ & Model Type \\
\hline 2711 & 0.23 & 0.03 & 13.1 & 772 & 1.92 & 139.49 & 267.4 & 29.7 & 0.26 & Hemisphere \\
\hline 2683 & 0.37 & 0.03 & 21.3 & 865 & 1.02 & 237.18 & 242.8 & 13.9 & 0.14 & \multirow{6}{*}{$30^{\circ}$ sphere-cone } \\
\hline 2684 & 0.29 & 0.01 & 16.8 & 850 & 1.27 & 191.44 & 244.0 & 9.0 & 0.18 & \\
\hline 2685 & 0.32 & 0.02 & 18.5 & 847 & 1.25 & 208.57 & 262.6 & 11.5 & 0.18 & \\
\hline 2686 & 0.16 & 0.01 & 9.2 & 971 & 3.37 & 96.16 & 322.5 & 23.9 & 0.48 & \\
\hline 2687 & 0.25 & 0.01 & 14.4 & 925 & 2.16 & 155.03 & 333.7 & 13.3 & 0.30 & \\
\hline 2689 & 0.20 & 0.01 & 11.4 & 1020 & 3.73 & 113.61 & 421.8 & 26.9 & 0.53 & \\
\hline 2697 & 0.27 & 0.03 & 15.6 & 791 & 2.28 & 113.35 & 263.13 & 1.40 & 0.35 & \multirow{7}{*}{$45^{\circ}$ sphere-cone } \\
\hline 2699 & 0.19 & 0.04 & 10.8 & 780 & 3.54 & 79.11 & 287.81 & 0.47 & 0.55 & \\
\hline 2701 & 0.18 & 0.05 & 10.6 & 770 & 3.53 & 79.37 & 276.54 & 0.77 & 0.53 & \\
\hline 2703 & 0.17 & 0.05 & 9.6 & 776 & 2.65 & 71.95 & 193.91 & 0.74 & 0.40 & \\
\hline 2704 & 0.18 & 0.04 & 10.5 & 756 & 2.33 & 80.23 & 198.01 & 1.46 & 0.37 & \\
\hline 2706 & 0.20 & 0.03 & 11.7 & 710 & 2.58 & 88.99 & 226.90 & 2.18 & 0.38 & \\
\hline 2707 & 0.23 & 0.06 & 13.3 & 706 & 2.56 & 100.19 & 245.15 & 0.72 & 0.37 & \\
\hline
\end{tabular}

\section{Summary}

A study of roughness-dominated boundary-layer transition was conducted on blunt-body geometries in hypersonic free-flight in carbon dioxide in order to test the applicability of an existing roughness-induced transition criterion to atmospheric entry missions at Mars or Venus. The tests were conducted in both air and $\mathrm{CO}_{2}$ in the NASA Ames Hypervelocity Free Flight Aerodynamic Facility ballistic range at speeds between $2.8 \mathrm{~km} / \mathrm{s}$ and 5.1 $\mathrm{km} / \mathrm{s}$ and freestream pressures between 50 Torr and 228 Torr. Distributed surface roughness was produced by gritblasting techniques, and each distribution was characterized by the mean roughness-element height. Transition onset 
locations were measured for each test, and laminar CFD solutions were used to compute the roughness Reynolds number at transition.

The critical-roughness-Reynolds-number correlating approach was found to well model transition onset and progression in $\mathrm{CO}_{2}$. The critical value of the roughness Reynolds number for transition onset was found to be 223 in $\mathrm{CO}_{2}$, and 259 in air. The uncertainty on $\mathrm{Re}_{\mathrm{kk}}$, tr for these experiments is estimated to be $\pm 25 \%$. Based on these results alone it appears easier for distributed roughness to trip the $\mathrm{CO}_{2}$ boundary layer to turbulence; i.e., for a specified roughness height, the critical roughness Reynolds number for flights in air was higher than the value for $\mathrm{CO}_{2}$. However, both mean values determined in these experiments fall within the uncertainty bounds of the previously-established critical value for transition onset in air of $250 \pm 20 \%$ [Refs. 1 and 3]. The mean value determined in air is nearly 1.2 times higher than the mean value in $\mathrm{CO}_{2}$, but smaller than the 1.3/1 ratio reported for isolated roughness elements in Ref. 8. Additional testing, especially for conditions approaching the smooth-wall asymptote would reduce the uncertainty.

\section{Acknowledgments}

This work was supported by the NASA Fundamental Aeronautics Hypersonics project and the Hypersonic Entry Decent and Landing project. Model and sabot designs are by David W. Bogdanoff, ERC Inc. Dinesh K. Prabhu, and David W. Bogdanoff were supported by the Space Technology Research and Development Contract NNA10DE12C from NASA Ames Research Center to ERC, Inc.

\section{References}

${ }^{1}$ Reda, D. C., "Review and Synthesis of Roughness-Dominated Transition Correlations for Reentry Applications," Journal of Spacecraft and Rockets, Vol. 39, No. 2, 2002, pp. 161-167.

2 Schiller, L., "Flow in Pipes," Handbook of Experimental Physics, Vol. 4, Pt. 4, Academic Press, Leipzig, Germany, 1932, pp. 189-192.

${ }^{3}$ Reda, D.C., Wilder, M.C., Bogdanoff, D.W., and Prabhu, D.K., "Transition Experiments on Blunt Bodies with Distributed Roughness in Hypersonic Free Flight”, Journal of Spacecraft and Rockets, Vol. 45, No. 2, March-April 2008, pp. $210-215$.

${ }^{4}$ Reda, D. C., Wilder, M. C., and Prabhu, D. K., "Transition Experiments on Slightly Blunted Cones with Distributed

Roughness in Hypersonic Flight," AIAA Journal, Vol. 50, No. 10, October 2012, pp. 2248-2254.

5 Hollis, B. R., "Distributed Roughness Effects on Blunt-Body Transition and Turbulent Heating," AIAA 2014-0238, 52

AIAA Aerospace Sciences Meeting, 13-17 January 2014.

${ }^{6}$ Dirling, R.B. Jr., “A Method for Computing Roughwall Heat Transfer Rates on Reentry Nosetips,” AIAA 73-763, AIAA 8th Thermophysics Conference, Palm Springs, CA, July 1973.

7 White, T. R., Mahzari, M., Bose, D., and Santos, J. A., "Post-flight Analysis of the Mars Science Laboratory Entry Aerothermal Environment and Thermal Protection System Response," AIAA 2013-2779, 44th AIAA Thermophysics

Conference, San Diego, CA, June 24-27, 2013.

${ }^{8}$ Reda, D. C., Wilder, M. C., and Prabhu, D. K., “Transition Experiments on Blunt Bodies with Isolated Roughness Elements in Hypersonic Free Flight," Journal of Spacecraft and Rockets, Vol. 47, No. 5, September-October 2010, pp. $828-835$.

9 Intrieri, P. F., and De Rose, C. E., "Flight Characteristics of Probes in the Atmospheres of Mars, Venus and the Outer Planets," Acta Astronautica, Vol. 4, pp. 789-799, 1977.

${ }^{10}$ Brown, J., Yates, L., Bogdanoff, D., Chapman, G., Loomis, M., and Tam, T., "Free Flight Testing in Support of the Mars

Science Laboratory Aerodynamics Database," Journal of Spacecraft and Rockets, Vol. 43, No. 2, pp. 293-302, 2006.

${ }^{11}$ Canning, T. N., Seiff, A., and James, C. S. (Ed.) "Ballistic Range Technology," AGARDograph No. 138, 1970 , p. 58.

${ }^{12}$ Wilder, M.C., Bogdanoff, D. W., and Cornelison, C. J., "Hypersonic Testing Capabilities at the NASA Ames Ballistic

Ranges," Invited paper to be presented at the 53 ${ }^{\text {rd }}$ AIAA Aerospace Sciences Meeting, Kissimmee, Florida, 5-9 January 2015.

${ }^{13}$ Wright, M. J., White, T., and Mangini, N., "Data-Parallel Line Relaxation (DPLR) Code User Manual, Acadia - Version 4.01.1,” NASA/TM-2009-215388, Oct. 2009.

${ }^{14}$ Gordon, S., and McBride, B. J., "Computer Program for Calculation of Complex Chemical Equilibrium Compositions and Applications, I: Analysis,” NASA RP-1311, October 1994.

${ }^{15}$ Baldwin, B.S. and Lomax, H. "Thin Layer Approximation and Algebraic Model for Separated Turbulent Flows," AIAA Paper 78-0257. Huntsville, AL, 1978.

${ }^{16}$ Wilder, M. C., Reda, D. C., and Prabhu, D. K., "Effects of Distributed Surface Roughness on Turbulent Heat Transfer Augmentation Measured in Hypersonic Free Flight," AIAA-2014-0512, 52 ${ }^{\text {nd }}$ AIAA Aerospace Sciences Meeting, 13-17 January 2014.

${ }^{17}$ Reda, D. C., and Raper, R. M., "Measurements of Transition-Front Asymmetries on Ablating Graphite Nosetips in Hypersonic Flight," AIAA Journal, Vol. 17, No. 11, Nov. 1979, pp. 1201-1207.

${ }^{18}$ Wilder, M.C., Reda, D.C., and Prabhu, D.K., "Heat-Transfer Measurements on Hemispheres in Hypersonic Flight through Air and $\mathrm{CO}_{2}$," AIAA-2011-3476, 42 ${ }^{\text {nd }}$ AIAA Thermophysics Conference, 27 - 30 June 2011, Honolulu, Hawaii. 